Research Article

\title{
Experimental Research and Simulation on the Mechanical Performance Degradation of Corroded Stud Shear Connectors
}

\author{
Bing Wang $\mathbb{D}^{1},{ }^{1}$ Xiaoling Liu $\mathbb{D}^{2},{ }^{2}$ and Jiantao $\mathrm{Du}^{3}$ \\ ${ }^{1}$ Faculty of Architectural, Civil Engineering and Environment, Ningbo University, Ningbo 315211, China \\ ${ }^{2}$ Faculty of Maritime and Transportation, Ningbo University, Ningbo 315211, China \\ ${ }^{3}$ Tianjin Transportation Research Institute, Tianjing 300012, China \\ Correspondence should be addressed to Xiaoling Liu; liuxiaolingseu@163.com
}

Received 6 June 2019; Revised 16 August 2019; Accepted 6 September 2019; Published 17 October 2019

Academic Editor: John D. Clayton

Copyright ( 2019 Bing Wang et al. This is an open access article distributed under the Creative Commons Attribution License, which permits unrestricted use, distribution, and reproduction in any medium, provided the original work is properly cited.

Electrochemical accelerated corrosion and tensile tests were conducted on six series of 30 stud specimens in this study to assess the various mechanical properties in corroded stud connectors. The results indicate that there is a gradual decline in mechanical properties (e.g., yield strength, ultimate strength, and plasticity) as stud corrosion rate increases. Degradation equations for these parameters were established via fitting analysis on the test data. A Gurson-Tvergaard-Needleman (GTN) constitutive model describing the tensile behavior of corroded studs was established based on mesodamage mechanics and finite element analysis. In the GTN model, the corrosion rate equals the original void volume fraction; the trial-and-error method was adopted to determine the relationship between the corrosion rate and material failure parameters. The finite element simulation results are in good agreement with the experimental results. The GTN model accurately simulates the uniaxial tensile behavior of the corroded stud.

\section{Introduction}

In steel-concrete composite beams, the stud connectors are key components which ensure shear transfer with the reinforced concrete slab. They are often structural failure points [1-3]. In the daily operation of an engineered bridge, traffic loads and temperature loads readily cause interface cracks among materials or cracks in the concrete slab. Upon the formation of cracks, the aggressive medium can easily reach the stud position further leading to stud corrosion, as shown in Figure 1. Corrosion degrades the mechanical properties of the studs and the bond performance between the concrete and studs, which ultimately degrades the structural performance of the entire bridge [4]. Correct, precise, and comprehensive understanding of the mechanical properties of corroded studs is the basis of durability assessment, life prediction, and the computer simulation analyses for steel-concrete composite bridges.

Many researchers have explored corrosion problems in a variety of steel components. Nakai et al. [5], for example, performed a corroded I-beam bending performance test using an artificial drilling method to simulate rust. They found that flexural capacity and ductility decrease sharply with the increase of the depth and the density of corrosion pits. Almusallam [6] adopted the constant current method to accelerate the corrosion of steel bars in a concrete structure, where the mass loss ratio was used to calibrate the corrosion rate. They found that when the corrosion rate exceeds $12 \%$, the steel bar presents brittle fracture. Garbatov et al. [7] obtained the material parameters of corroded beam specimens through a regression analysis of tensile strength test data. Feng et al. [8] discussed the influencing factors of stress-induced corrosion in steel bars. The results showed that the corrosion behavior of the rebar in mortars is strongly affected by the deterioration of the interface between the concrete and rebar. Chen et al. [9] investigated the behavior of corroded steel fibers with various levels of corrosion levels to find that the nominal tensile strength of the fibers decreases as corrosion increases. Pitting corrosion is also shown to reduce the actual tensile strength of steel fibers, while uniform corrosion has little effect. Zhang et al. [10] studied the effect of corroded prestressed steel bars/ 


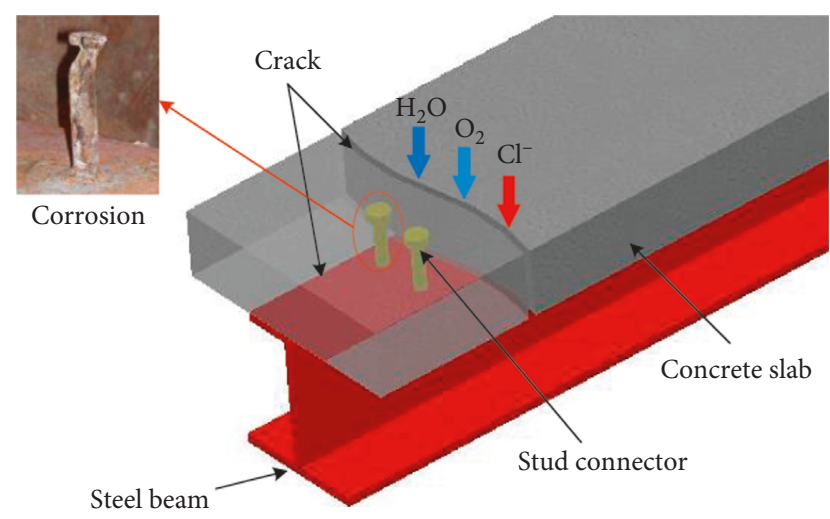

Figure 1: Stud corrosion in the steel-concrete composite beam.

strands on the fatigue behavior of partially prestressed concrete beams. They found that deflection and cracks develop quicker and grow wider in corroded beams as stiffness degradation increases compared to that of uncorroded beams. Guo et al. [11] used probabilistic finite element analysis to evaluate time-dependent reliability in strengthened PSC box-girder bridges. They effectively simulated concrete shrinkage, creep and cracking, and corrosion and stress relaxation in steel materials. Liu et al. [12] proposed a stochastic time-variant reliability assessment method considering the combined effect of corrosion and cyclic loading to evaluate the safety of suspenders. Previous studies on corroded steel components have mainly centered on plates and bars, while the corrosion problem in the stud connectors of steel-concrete composite structures is yet unresolved.

Most finite element simulations of corroded steel components are conducted from the macro perspective $[13,14]$. Because of the particular scale of the mesovoid, explicit modeling is not suitable for simulation analysis [15]. It is practical, however, for using damage variables to describe corrosion evolution characteristics from the mechanics point of view. The key point in any damage constitutive model is effectively introducing mesodefects into the macrovolume element. Such a damage constitutive model can also help to predict the macroconstitutive relationship [16]. Gurson proposed a model in which the constitutive relationship is analyzed by the mesomechanic homogenization method; he investigated an isolated spherical void in a continuum media and derived the pressure dependent yield function accordingly. However, the Gurson model does not account for intervoid effects. Tvergaard and Needleman modified the Gurson model to include a yield condition which encompasses the interaction among voids, the Gurson-Tvergaar-Needleman (GTN) model $[17,18]$. The GTN model can also be used to describe the tensile behavior of corroded studs.

In this paper, different corrosion rates of studs were selected through an accelerated corrosion method and assessed as per their effects on the mechanical properties of stud connectors via the tensile test. The change laws of various mechanical properties (e.g., yield strength, ultimate strength, and elongation) of corroded stud connectors were analyzed accordingly. The tensile behavior of corroded studs was also investigated by the GTN constitutive model based on mesodamage mechanics and finite element simulation.

\section{Electrochemical Accelerated Corrosion Test}

2.1. Electrochemical Accelerated Corrosion Mechanism. The stud connectors were immersed in $5 \% \mathrm{NaCl}$ solution [19] with a DC power supply. The positive terminal and the negative terminal of the DC power supply were connected with the stud connectors and the copper plate, respectively. Water in the electrolyte was electrolyzed into hydrogen ions and hydroxyl ions (i.e., $\mathrm{H}^{+}$and $\mathrm{OH}^{-}$) once the DC power supply was switched on. $\mathrm{H}^{+}$moved to the cathode and $\mathrm{OH}^{-}$ moved toward the anode while the stud lost an electron and an oxidation reaction occurred, whereas the cathodic material obtained an electron and a reduction reaction occurred. A stable current eventually formed leading to a closed loop, as shown in Figure 2. The reaction equation is as follows:

$$
\begin{aligned}
& \text { anodic reaction: } \mathrm{Fe}-2 \mathrm{e} \longrightarrow \mathrm{Fe}^{2+} \\
& \text { cathodic reaction: } \mathrm{O}_{2}+2 \mathrm{H}_{2} \mathrm{O}+4 \mathrm{e} \longrightarrow 4 \mathrm{OH}^{-}
\end{aligned}
$$

Rust formation is a step-wise process. $\mathrm{Fe}^{2+}$ meets with $\mathrm{OH}^{-}$in the transmission process and $\mathrm{Fe}(\mathrm{OH})_{2}$ is generated. Further, $\mathrm{Fe}(\mathrm{OH})_{2}$ and $\mathrm{O}_{2}$ are reacted to produce $\mathrm{Fe}(\mathrm{OH})_{3}$. As time progresses, $\mathrm{Fe}(\mathrm{OH})_{3}$ further turns into $n \mathrm{Fe}_{2} \mathrm{O}_{3} \cdot m \mathrm{H}_{2} \mathrm{O}$ (red rust). A loose rust layer thus forms on the surface of the stud.

2.2. Equation of Electrochemical Accelerated Corrosion Test Control. Faraday's Law [20] is needed to control the corrosion rate of studs, where the amount of a substance present at an electrode in the battery is proportional to the total electric charge passed through the substance. This can be expressed as follows:

$$
Q=m F
$$

where $Q$ is the total electric charge, $m$ is the amount of the substance, and $F$ is the Faraday constant $(96484 \mathrm{C} / \mathrm{mol})$.

Assuming the value of the anode current per unit anode area is $i(i=Q / t)$, the mass of the corroded iron per unit time is then given by

$$
w=\frac{M m}{n t}=\frac{M Q}{n t F}=\frac{M i}{n F},
$$

where $w$ is the mass loss of the stud per unit area and per second, the unit is $\mathrm{g} / \mathrm{s} ; t$ is the corrosion time; $n$ is a metal valence, the valence of iron is 2 ; and $M$ is the relative molecular mass of the metal or the relative atomic mass.

If the stud surface area is $A$ and the current is $I$, the mass loss for stud $(\Delta m)$ on corrosion time $t$ is expressed as

$$
\Delta m=A \cdot t \cdot w .
$$

Meanwhile,

$$
I=A \cdot i .
$$

By equations (3) (5), it can be obtained that 


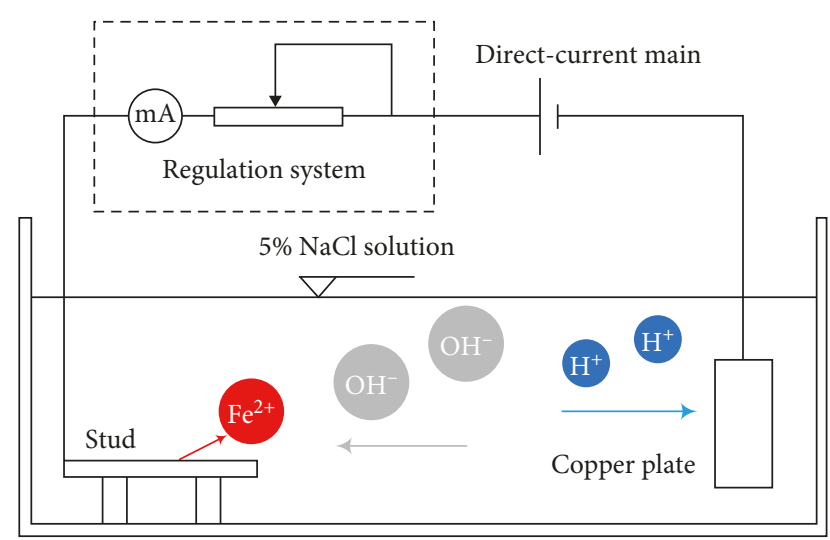

FIGURE 2: Experimental setup of the electrochemical accelerated corrosion test.

$$
\Delta m=M \frac{I}{n F} t
$$

Equation (6) can be used to calculate the required time $t$ to achieve a predetermined corrosion rate.

2.3. Corrosion Test. Stud type $(\mathrm{M} 13 \times 180)$ applied in the actual bridges was selected. Its actual diameter is $12.96 \mathrm{~mm}$ and the actual length is $178 \mathrm{~mm}$. The material type is ML-15. The specific chemical composition of the stud is listed in Table 1.

The stud specimens were preprocessed prior to the corrosion test. To conveniently chuck clamp the studs during the tensile test, the heads were removed. Numerous threads were carved in the head and tail of each stud to increase the friction force between the chuck and the stud. The studs were then washed with absolute alcohol, and both ends were sealed with an epoxy resin and a heat shrinkable tube; the middle exposed length of the stud was $70 \mathrm{~mm}$. Finally, 30-cm copper wires were welded in one end of the stud. Figure 3 shows the preparation and the electrochemical corrosion test process.

Six series of corrosion tests with different corrosion rates were designed for this study. In each series, five studs were subjected to corrosion over the same time period with the same electric current. After the experiment, the corroded stud was first cleaned with hydrochloric acid solution $(12 \%$ concentration) and then neutralized with saturated limewater. The cleaned stud was dried for four hours in an oven, and then its mass was weighed on an electronic said $(0.01 \mathrm{~g}$ accuracy). Here, it was assumed that corrosion only occurs in the exposed length range of the stud and that the mass of the stud is uniformly distributed along its length direction. Thus, the stud corrosion rate can be calculated as follows:

$$
\rho=\frac{m_{0}-m_{\rho}}{m_{0}(l / L)}
$$

where $m_{0}$ is the initial mass of the stud, $m_{\rho}$ is the mass of the corroded stud, $l$ is the exposed length $(70 \mathrm{~mm})$, and $L$ is the total length of the stud.

Table 2 shows a comparison between the test and theoretical prediction results. The theoretical prediction corrosion rate is very close to the actual corrosion rate, which indicates that the equation to control the stud corrosion rate is feasible. Additionally, when the corrosion rate is less than or equal to $7 \%$, the theoretical prediction corrosion rate is slightly underestimated; when the corrosion rate is more than $7 \%$, the theoretical prediction corrosion rate is slightly overestimated. This is mainly due to the adsorption of iron oxide on the surface of the stud during the test. At the beginning of the test, the energization was strong and the electrochemical reaction was stable and intense; thus, the actual corrosion rate was greater than the theoretical prediction. However, as the reaction progressed, a large amount of iron oxide adhered to the studs and the copper plate, hindering the reaction and driving the theoretical rate above the actual corrosion rate.

Figure 4 shows the appearance of the stud specimens after testing at different corrosion rates. The corrosion surface of the stud appears to have grown increasingly uneven as the corrosion rate increased, accompanied by rust pits on the surface.

2.4. Tensile test. It is true that stud connectors are shearbased components in actual use, but tensile strength is more easily obtained under normal conditions. In EC4 and AASHTO codes, the tensile strength of studs is used as an index for calculating the shear strength of studs. The tensile mechanical properties of the studs were tested in this paper.

Tensile tests were conducted in this study to assess the mechanical behavior, including strength, elongation, and elastic modulus of studs under different corrosion rates.

Before the test, every $5 \mathrm{~mm}$ within the $5 d$ range of the stud was marked with a color pen in order to measure the elongation. The experiment was run on a microcomputer hydraulic universal testing machine with a loading rate of $5 \mathrm{~N} / \mathrm{mm}^{2} \cdot \mathrm{s}^{-1}$, as shown in Figure 5.

Three material parameters, yield strength, ultimate strength, and elongation, were determined by experiments and expressed in nominal terms. The nominal strength is the ratio of the actual load to the nominal section area. The relative elongation can be expressed as a relatively nominal uniform elongation. In this study, elongation was calculated as follows:

$$
\delta=\frac{L_{5}-5 d}{5 d} \times 100 \%,
$$

where $\delta$ is the elongation (\%), $5 d$ is the original mark distance, and $L_{s}$ is the measured length between notches after fracture.

2.5. Test Results and Analysis. Figure 6 shows where the stress-strain relationship curve of the studs corroded at different rates trends steadily downward as corrosion rate increases. Regardless of the extent of corrosion, the stressstrain curve shows continuous yielding with no obvious yield point. To this effect, the yield strength can be determined by the residual strain of $0.2 \%$ after unloading [21].

Moreover, it was found that the stress-strain relationship of the corroded studs can be divided into three stages: an 
TABle 1: Chemical composition of ML-15.

\begin{tabular}{lc}
\hline Elements & Contents (\%) \\
\hline $\mathrm{C}$ & $0.12 \sim 0.16$ \\
$\mathrm{Si}$ & $0.05 \sim 0.08$ \\
$\mathrm{Mn}$ & $0.32 \sim 0.38$ \\
$\mathrm{Alt}$ & $0.034 \sim 0.040$ \\
$\mathrm{P}$ & $0.012 \sim 0.016$ \\
$\mathrm{~S}$ & $\leq 0.009$ \\
$\mathrm{Ni}$ & $\leq 0.010$ \\
$\mathrm{Cr}$ & $\leq 0.023$ \\
$\mathrm{Cu}$ & $\leq 0.010$ \\
\hline
\end{tabular}

elastic stage, elastoplastic stage, and plastic stage. In the elastic stage, the stress increases from zero to the yield strength. The relationship between stress and strain is linear and the slope reflects the nominal elastic modulus. In the elastic-plastic stage, the stress increases to the ultimate strength nonlinearly. In the plastic stage, the strain increases sharply while the stress slowly decreases.

\subsection{Degradation Model of Corroded Stud Mechanical} Properties. The mechanical properties of the studs are altered by corrosion, which is reflected in the constitutive model. As shown in Figure 6, the mechanical parameters of the stud degraded considerably as the corrosion rate changed throughout the experiment.

A regression model was determined according to the trends observed in the test. The parameters were calculated via the principle of the least square method, and a regression curve equation was obtained.

The relative value of yield strength $k_{\mathrm{y}}$, relative value of ultimate tensile strength $k_{\mathrm{t}}$, relative value of elongation $k_{\mathrm{e}}$, and relative value of elastic modulus $k_{\mathrm{em}}$ can be defined as shown in equations (9)-(12), respectively:

$$
\begin{gathered}
k_{\mathrm{y}}=\frac{\sigma_{\mathrm{s}}}{\sigma_{\mathrm{s} 0}}, \\
k_{\mathrm{t}}=\frac{\sigma_{\mathrm{b}}}{\sigma_{\mathrm{b} 0}}, \\
k_{\mathrm{e}}=\frac{\delta}{\delta_{0}}, \\
k_{\mathrm{em}}=\frac{E}{E_{0}},
\end{gathered}
$$

where $\sigma_{\mathrm{s}}$ is the yield strength of corroded studs, $\sigma_{\mathrm{b}}$ is the ultimate strength of corroded studs, $\delta$ is the elongation of corroded studs, $E$ is the elastic modulus of corroded studs, and $\sigma_{\mathrm{s} 0}, \sigma_{\mathrm{b} 0}, \delta_{0}$, and $E_{0}$ are the corresponding uncorroded stud parameters.

Figure 7 gives the variation of several mechanical properties with the corrosion rate. According to Figures 7(a) and 7(b), the yield strength and ultimate strength of the corroded stud were less than those before corrosion, which exhibited a linear degradation with the corrosion rate. There are two main reasons for the degradation: (1) an effective area reduction of the corroded stud and (2) the stress concentration caused by the stud's uneven surface. It is worth noting that the dispersion degree of the stud strength was larger in the case of high corrosion rate. Evidently, when the corrosion rate is relatively high, the corrosion morphology of the stud has a significant influence on the stud's strength.

Figure $7(\mathrm{c})$ shows where the elongation decreased nonlinearly as the corrosion rate increased, i.e., ductility reduction occurred over the course of the test. Elongation was reduced at a higher rate than nominal strength, which is consistent with the change law of corroded steel bars $[22,23]$.

Figure 7 (d) shows that the nominal elastic modulus also decreased as the corrosion rate increased, however, the decline is not significant. The fitting coefficient of determination is also fairly low (only 0.7518), indicating sizable fluctuations. The minimum value of elastic modulus is 196.0 GPa across all the specimens, and the error is less than $2 \%$ compared with the initial value. In effect, the elastic modulus of the stud is basically not influenced by the corrosion rate.

The mechanical properties of the corroded studs tested in this study degraded in a similar manner to those of ordinary steel bars. The degradation is not only related to the corrosion rate but also to the precise corrosion morphology of the studs. The fitting results shown in Figure 7 were used to establish the mechanical degradation model for the corroded studs:

$$
\begin{aligned}
\sigma_{\mathrm{s}} & =\sigma_{\mathrm{s} 0} k_{\mathrm{y}}=\sigma_{\mathrm{s} 0}(0.9986-1.3506 \rho), \\
\sigma_{\mathrm{b}} & =\sigma_{\mathrm{b} 0} k_{\mathrm{t}}=\sigma_{\mathrm{b} 0}(1.0038-1.1914 \rho), \\
\delta & =\delta_{0} k_{\mathrm{e}}=\delta_{0}\left(0.9613 e^{-2.09 \rho}\right) .
\end{aligned}
$$

\subsection{Finite Element Analysis}

2.7.1. Gurson-Tvergaar-Needleman (GTN) Model. For most engineering alloys, ductile fracture usually occurs in three stages: void nucleation, void growth, and void coalescence [24], as shown in Figure 8.

Gurson-Tvergaar-Needleman (GTN) constitutive model can be used to describe the effect of voids on the plastic properties of the metal materials. Assuming that the mass loss rate of the corroded stud is equal to the original void volume fraction, finite element analysis can be applied to describe the tensile behavior of the corroded studs by introducing the GTN constitutive model. It is expressed as

$$
\Phi=\frac{\sigma_{\mathrm{eq}}^{2}}{\sigma_{0}^{2}}+2 q_{1} f^{*} \cosh \left(\frac{3 q_{2} \sigma_{\mathrm{m}}}{2 \sigma_{0}}\right)-\left(1+q_{3} f^{* 2}\right)=0,
$$

where $\sigma_{\mathrm{eq}}$ is the macroscopic mises equivalent stress, $\sigma_{\mathrm{m}}$ is the macroscopic hydrostatic stress, $\sigma_{0}$ is the equivalent yield stress, and $q_{1}, q_{2}$, and $q_{3}$ are the proposed model parameters [25], respectively. While $q_{3}$ is equal to $q_{1}^{2} \cdot f^{*}$ is the void volume fraction. 


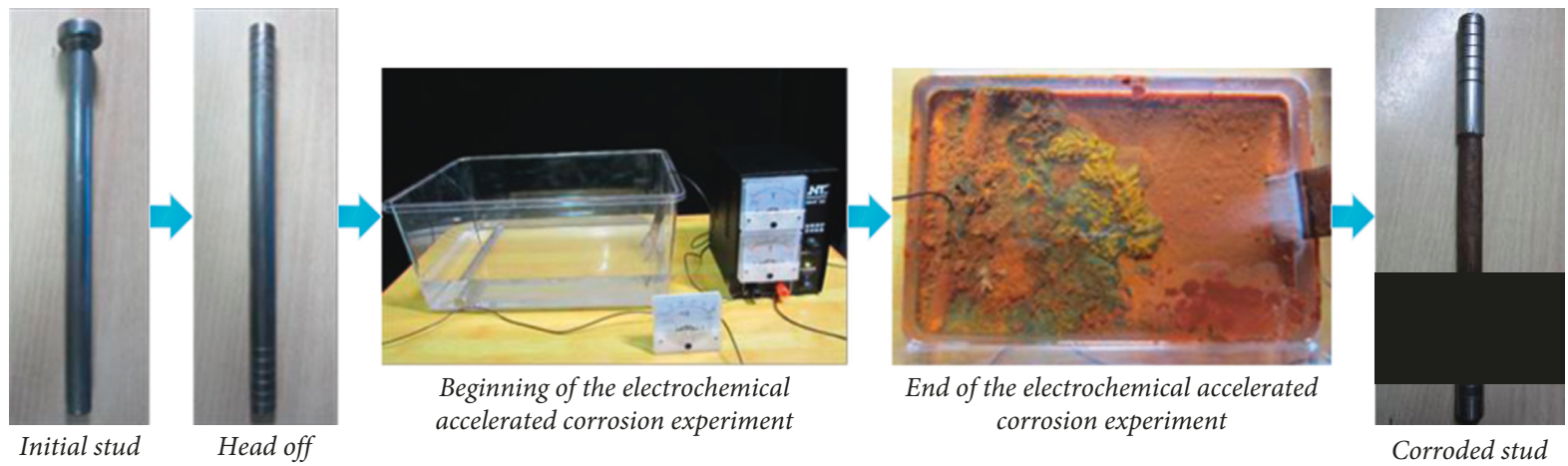

Figure 3: Stud electrochemical accelerated corrosion process.

TABLE 2: Comparison between experimental and theoretical stud corrosion rate values.

\begin{tabular}{lccccc}
\hline $\begin{array}{l}\text { Test } \\
\text { number }\end{array}$ & $\begin{array}{c}\text { Number of } \\
\text { tests }\end{array}$ & $\begin{array}{c}\text { Corrosion current density } \\
\left(\mathrm{mA} / \mathrm{cm}^{2}\right)\end{array}$ & $\begin{array}{c}\text { Corrosion time } \\
(h)\end{array}$ & $\begin{array}{r}\text { Theoretical corrosion rate } \\
\rho_{f}(\%)\end{array}$ & $\begin{array}{c}\text { Measured corrosion rate } \\
\rho_{s}(\%)\end{array}$ \\
\hline$T-1$ & 5 & 0 & 0 & 0 & 0 \\
$\rho_{f} / \rho_{s}$
\end{tabular}

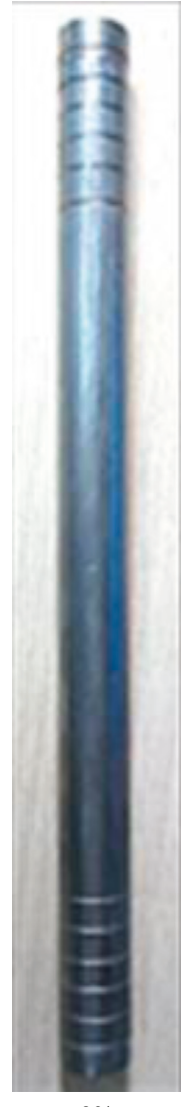

$0 \%$

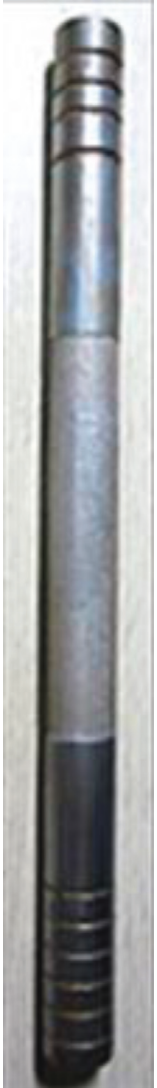

$5.66 \%$

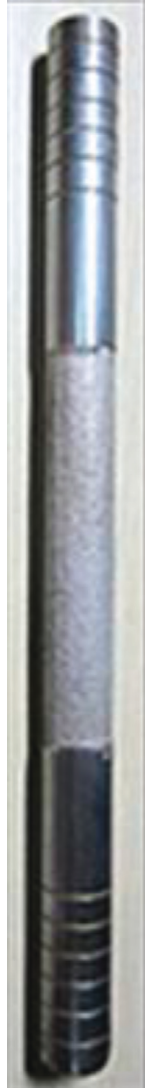

$7.25 \%$

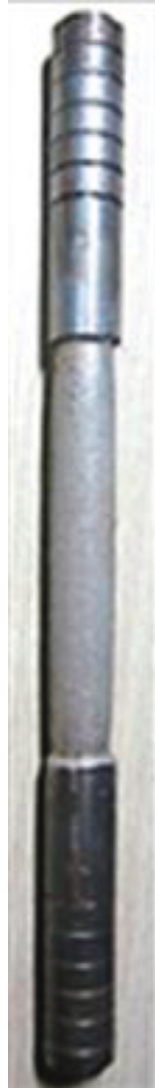

$9.36 \%$

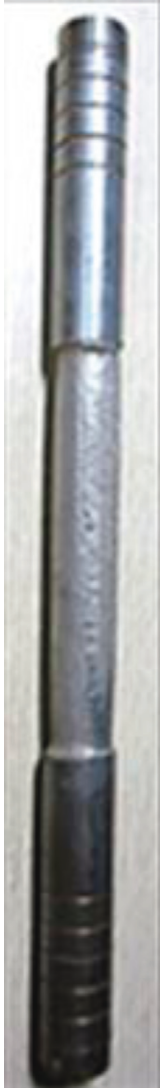

$14.21 \%$

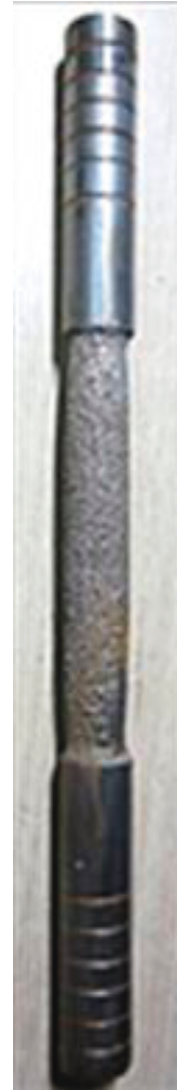

$18.83 \%$

(a)

(b)

(d)

(e)

(f)

Figure 4: Studs at different corrosion rates. (a) $0 \%$. (b) $5.66 \%$. (c) $7.25 \%$. (d) $9.36 \%$. (e) $14.21 \%$. (f) $18.83 \%$. 


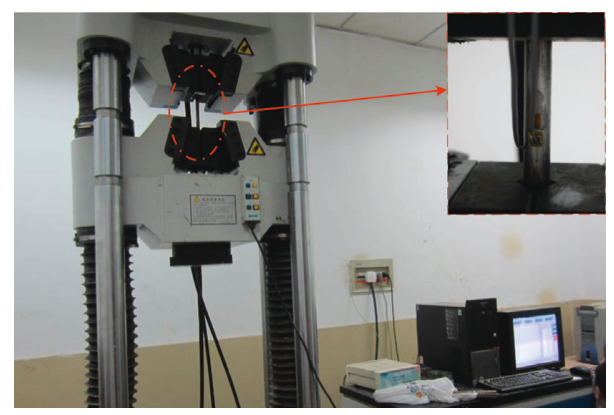

FIGURE 5: Tensile test equipment.

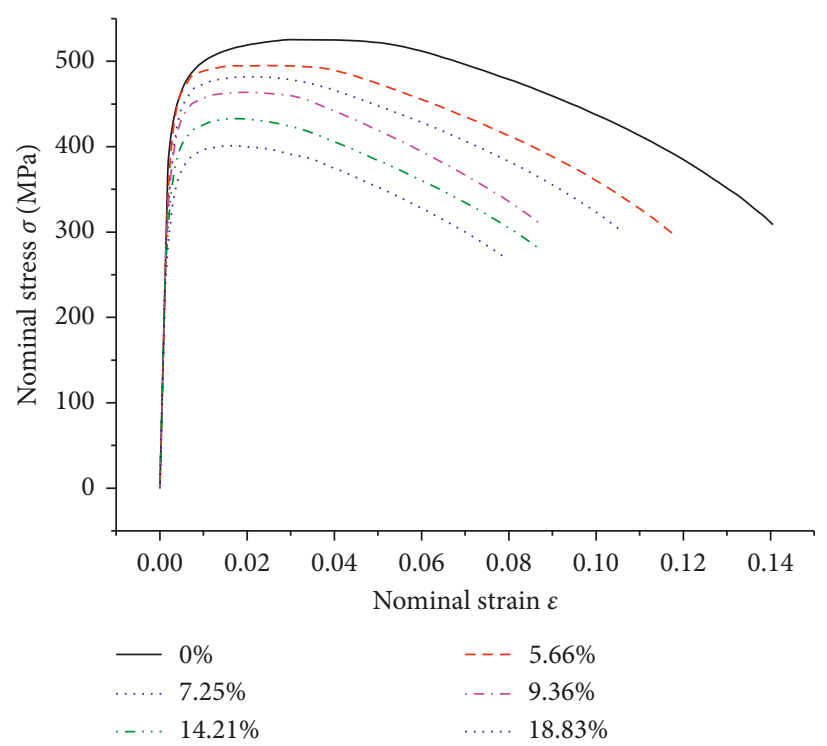

Figure 6: Stress-strain curves for studs with different corrosion rates.

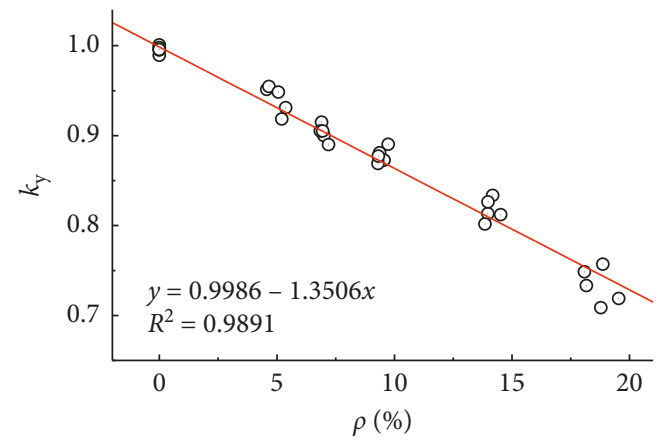

(a)

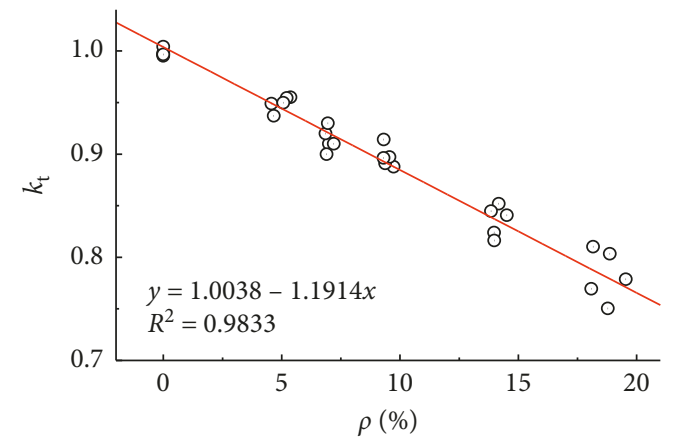

(b)

FIgURE 7: Continued. 


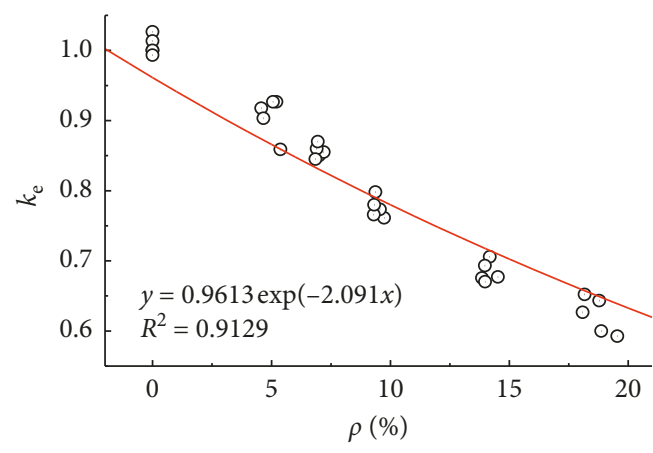

(c)

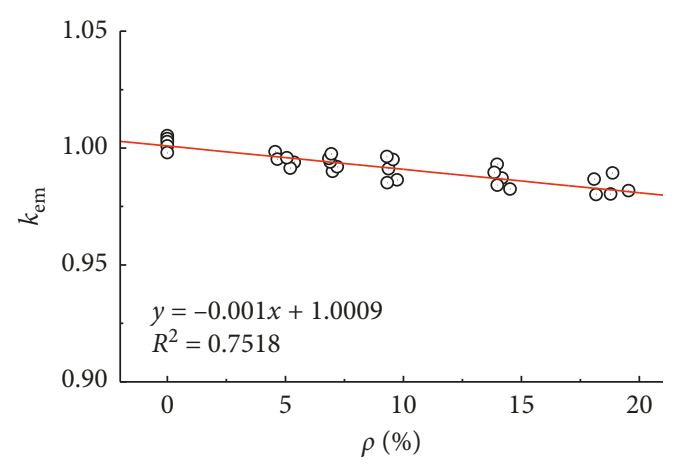

(d)

FiguRE 7: Mechanical properties varying with corrosion rate. (a) Yield strength. (b) Ultimate strength. (c) Elongation ratio. (d) Elastic modulus.

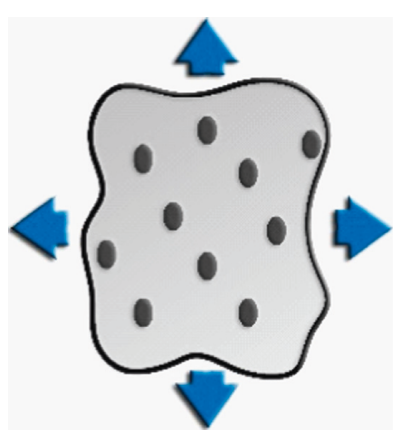

(a)

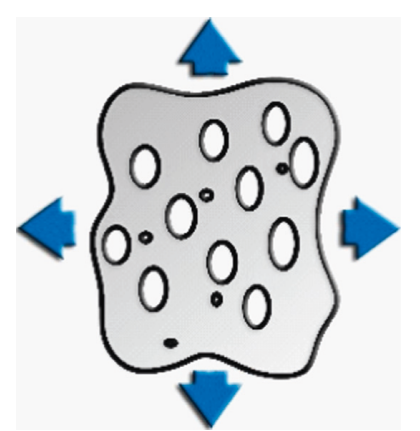

(b)

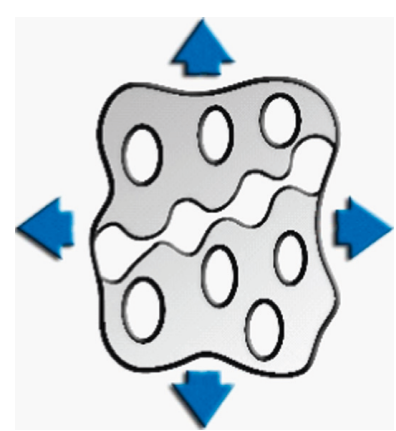

(c)

FIGURE 8: Schematic diagram of ductile fracture mechanisms of the porous metal. (a) Void nucleation. (b) Void growth. (c) Void coalescence.

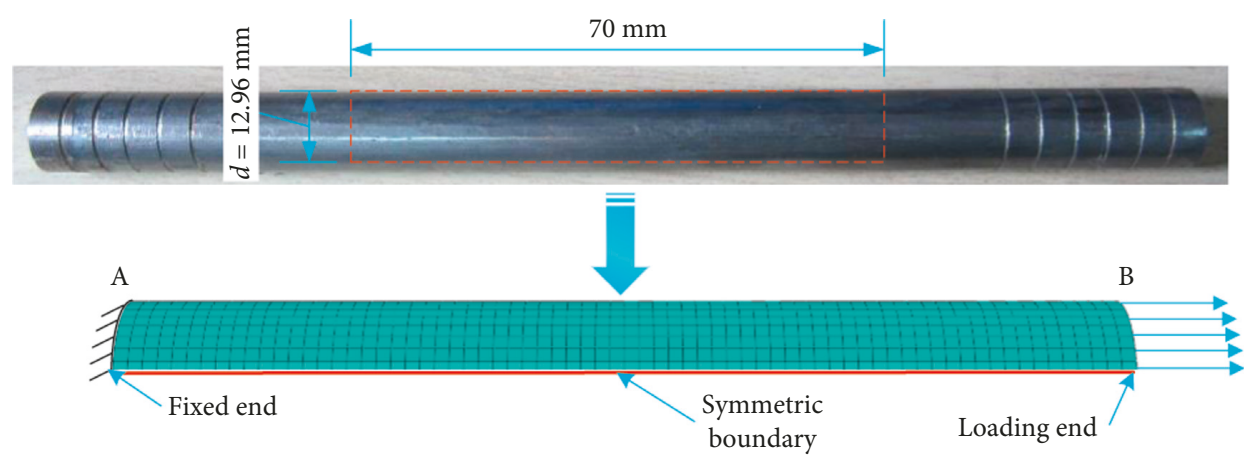

FIGURE 9: Finite element analysis model of the stud.

TABLE 3: GTN model parameters.

\begin{tabular}{ccccccccc}
\hline & Material parameters & \multicolumn{3}{c}{ Void nucleation } & \multicolumn{3}{c}{ Void propagation/coalescence } \\
$q_{1}$ & $q_{2}$ & $q_{3}$ & $\varepsilon_{\mathrm{N}}$ & $S_{\mathrm{N}}$ & $f_{\mathrm{N}}$ & $f_{0}$ & $f_{\mathrm{c}}$ \\
\hline 1.5 & 1 & 2.25 & 0.3 & 0.1 & 0.04 & $\rho$ & $0.08+\rho$ \\
\hline
\end{tabular}




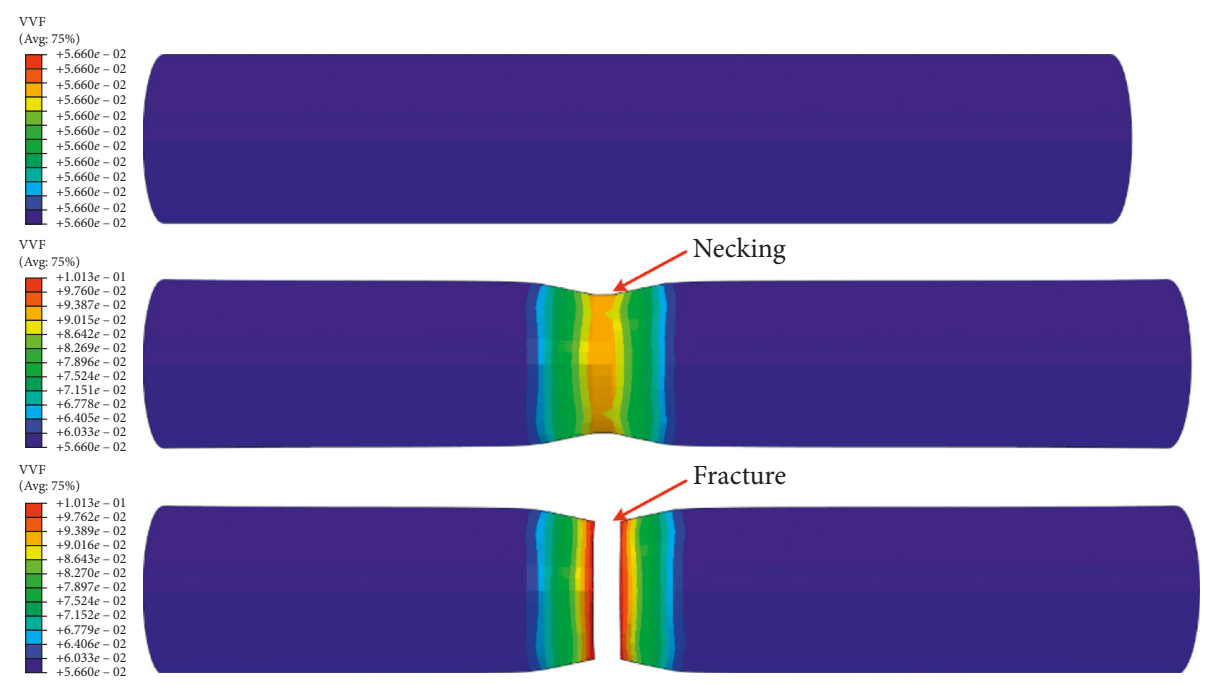

(a)

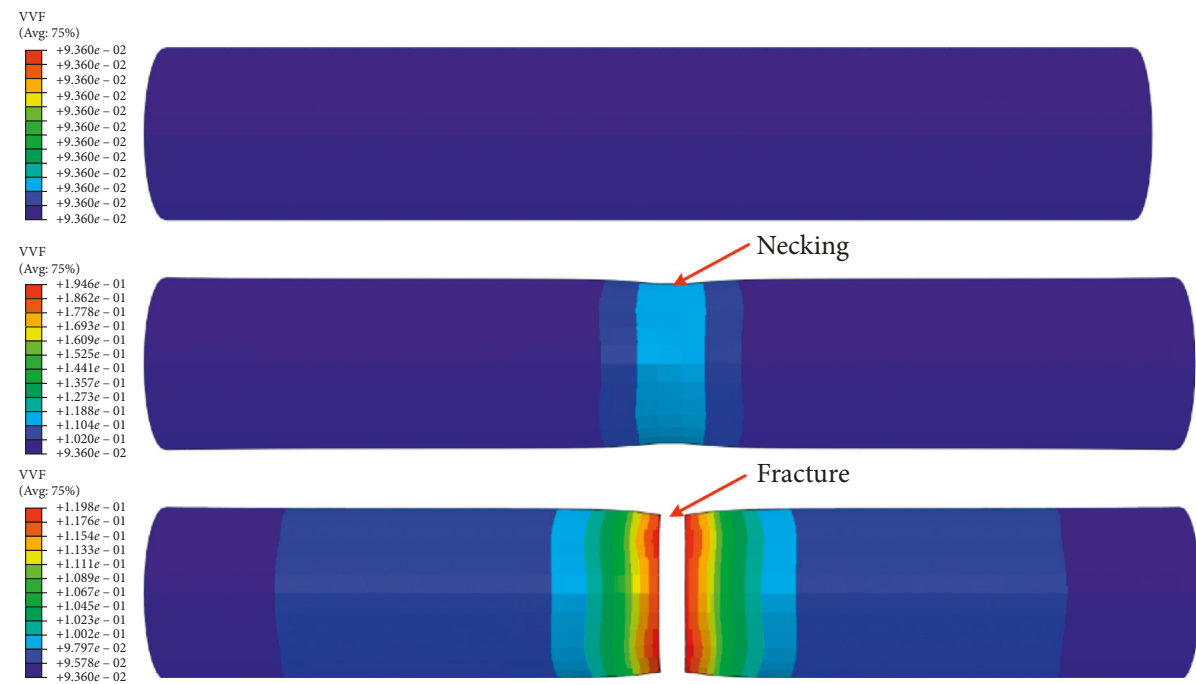

(b)

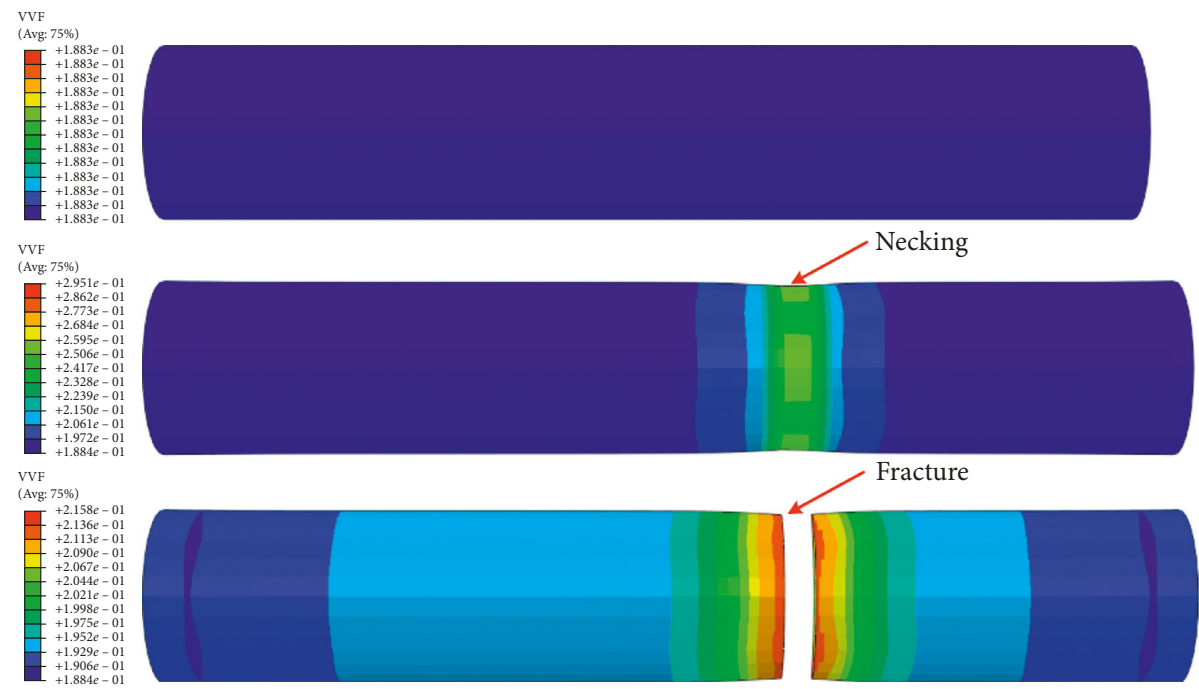

(c)

Figure 10: Stud damage evolution under different corrosion rates in the tensile process. (a) $f_{0}=5.66 \%$. (b) $f_{0}=9.36 \%$. (c) $f_{0}=18.83 \%$. 


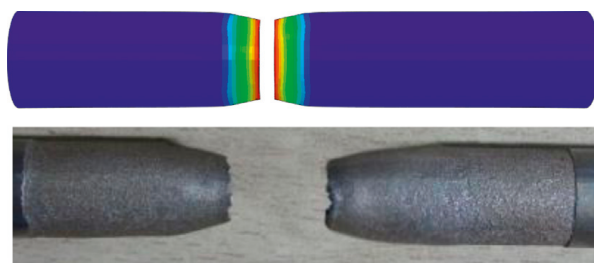

(a)

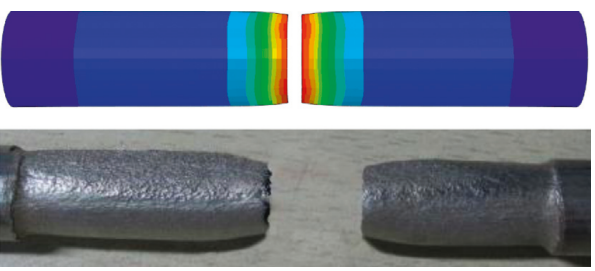

(b)

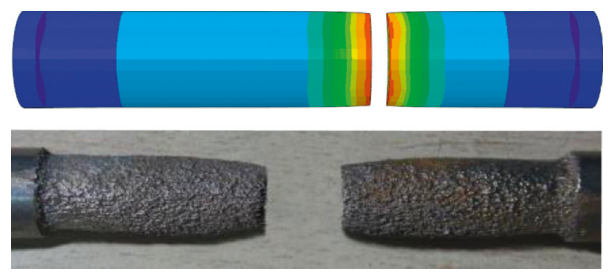

(c)

Figure 11: Comparison of the failure modes between test and finite element analyses. (a) $f_{0}=5.66 \%$. (b) $f_{0}=9.36 \%$. (c) $f_{0}=18.83 \%$.

The void volume fraction $f^{*}$ is expressed in the following formula:

$$
f^{*}= \begin{cases}f, & f \leq f_{\mathrm{c}}, \\ f_{\mathrm{c}}+\frac{f_{\mathrm{u}}^{*}-f_{\mathrm{c}}}{f_{\mathrm{F}}-f_{\mathrm{c}}}\left(f-f_{\mathrm{c}}\right), & f>f_{\mathrm{c}},\end{cases}
$$

where $f_{\mathrm{c}}$ is the critical void volume fraction at the beginning of the void polymerization, $f_{\mathrm{F}}$ is the void volume fraction for the disrupted materials, and $f_{\mathrm{u}}^{*}$ is the critical void volume fraction when the stress bearing capacity is zero.

The porous propagation of materials includes the void growth rate and the void nucleation rate, as shown in equation (16).

$$
\dot{f}=\dot{f}_{\text {growth }}+\dot{f}_{\text {nucleation }} \text {. }
$$

The growth rate is expressed by equation (17) under the assumption of incompressible plasticity of the matrix material. The nucleation rate of the void can be expressed by equation (18).

$$
\dot{f}_{\text {growth }}=(1-f) \dot{\varepsilon}_{\mathrm{kk}}^{\mathrm{p}},
$$

where $\dot{\varepsilon}_{\mathrm{kk}}^{\mathrm{p}}$ is the plastic hydrostatic strain.

$$
\dot{f}_{\text {nucleation }}=A \dot{\varepsilon}_{0}=\frac{f_{\mathrm{N}}}{S_{\mathrm{N}} \sqrt{2 \pi}} \exp \left[-\frac{1}{2}\left(\frac{\varepsilon_{0}^{\mathrm{p}}-\varepsilon_{\mathrm{N}}}{S_{\mathrm{N}}}\right)\right] \dot{\varepsilon}_{0},
$$

where $\varepsilon_{\mathrm{N}}$ is the average strain at void nucleation, $S_{\mathrm{N}}$ is the standard deviation of nuclear strain, $f_{\mathrm{N}}$ is the volume fraction size of a nuclear particle, and $A$ is the void nucleation coefficient.

2.7.2. Finite Element Model. A finite element model of the middle stud $(70 \mathrm{~mm})$ was established. In view of the geometric symmetry of the stud, the $1 / 2$ model was thus established and the symmetric boundary conditions were applied, as illustrated in Figure 9. The eight-node solid element C3D8R was used [26]. According to the meshing size of the unit in the references $[16,27]$, the model was meshed with the unit size of $1 \mathrm{~mm} \times 1 \mathrm{~mm} \times 1 \mathrm{~mm}$.

In this model, the A end is a fixed end and the B end is a loading end. The displacement loading method was adopted, and the loading direction is shown in Figure 9. The displacement value was $6 \mathrm{~mm}$.

The stress-strain curve of the nondestructive material was applied, as shown in Figure 6, to further explore the model parameters. The elastic modulus $E$ in this case is $200 \mathrm{GPa}$ and Poisson's ratio $\mu$ is 0.3 . The GTN constitutive model was used to characterize the material's plasticity behavior, where $q_{1}, q_{2}$, and $q_{3}$ are the constitutive parameters to be determined; $\varepsilon_{\mathrm{N}}, S_{\mathrm{N}}$, and $f_{\mathrm{N}}$ are the unknown void evolution parameters and $f_{\mathrm{c}}$, and $f_{\mathrm{F}}$ are the unknown material failure parameters. There are eight undetermined parameters in this model. The reasonable parameters are directly related to the applicability of the GTN model.

Tvergaard and Hutchinson [25] suggested three constitutive parameters as constants: $q_{1}=1.5, q_{2}=1$, and $q_{3}=q_{1}^{2}$. The void nucleation parameters can be analyzed according to the normal distribution of the nucleation mode. Usually, $\varepsilon_{\mathrm{N}}=0.3$ and $S_{\mathrm{N}}=0.1$ [28]. The parameter $f_{\mathrm{N}}$ has a certain effect on the softening region in the uniaxial tensile stressstrain curve. It is usually taken as 0.04 [29]. $f_{\mathrm{c}}$ and $f_{\mathrm{F}}$ are not constant; they are related to the initial porosity $f_{0}$ and the stress triaxiality Zhang et al. [30] found that $f_{\mathrm{F}}$ affects the shape of the tensile curve in the tightening phase and defines the relationship between $f_{\mathrm{F}}$ and $f_{0}: f_{\mathrm{F}}=0.15+2 f_{0}$. Xu and Qian [16] obtained relevant relationships by means of parameter fitting regression. The relationship between the initial corrosion rate $f_{0}$ with $f_{\mathrm{F}}$ and $f_{\mathrm{c}}: f_{\mathrm{c}}=0.1+f_{0}$ and $f_{\mathrm{F}}=0.15+f_{0}$. In the present study, the two were considered to be linear. The finite element simulation was matched to actual test results by trial and error and the following relationship was obtained: $f_{\mathrm{c}}=0.08+f_{0}$ and $f_{\mathrm{F}}=0.12+f_{0}$.

After confirming the values of $q_{1}, q_{2}, q_{3}, S_{\mathrm{N}}$, and $f_{\mathrm{N}}$, the corrosion rate was defined as $f_{0}$. Different combinations of material failure parameters were selected, and a regression was carried out to ensure the calculated response curves 

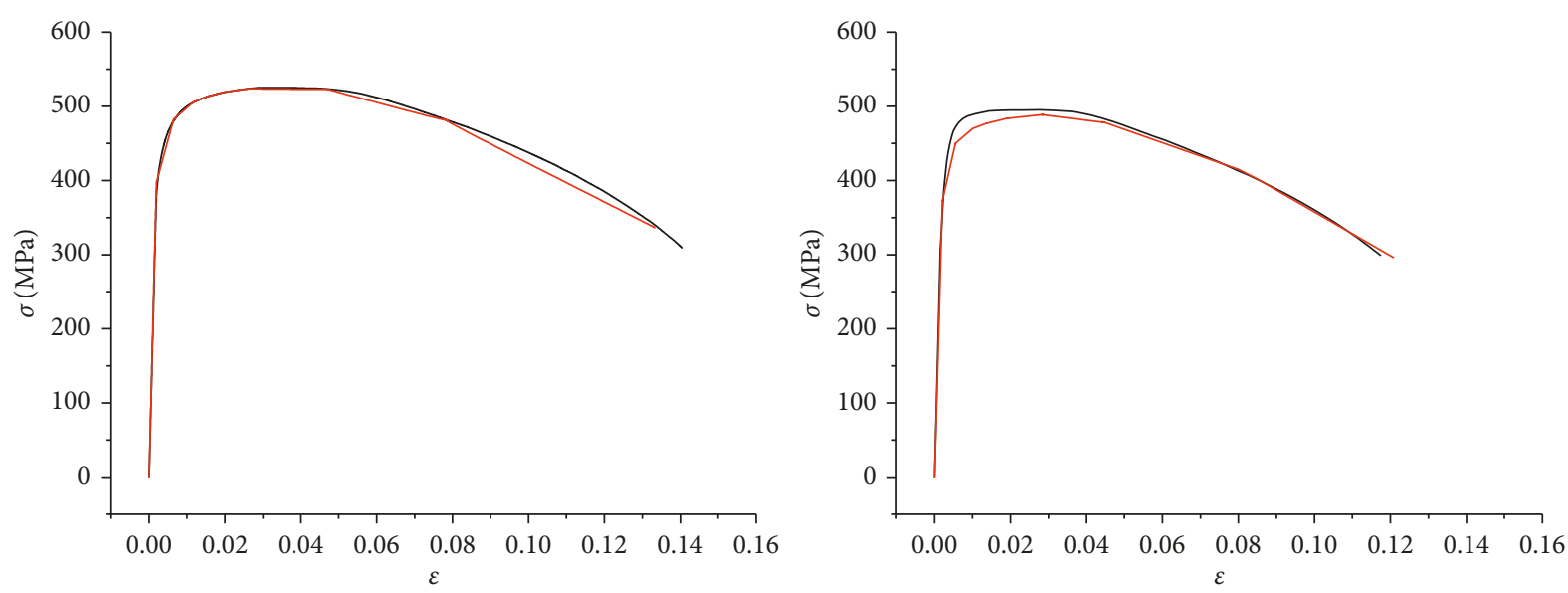

$\rho=0 \%$

_ Experimental values

_ Calculated values

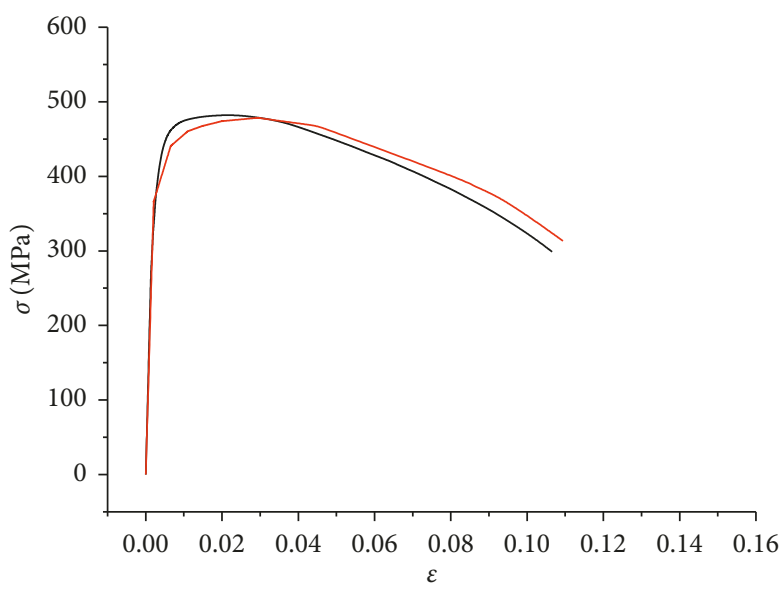

$\rho=5.66 \%$

— Experimental values

_ Calculated values

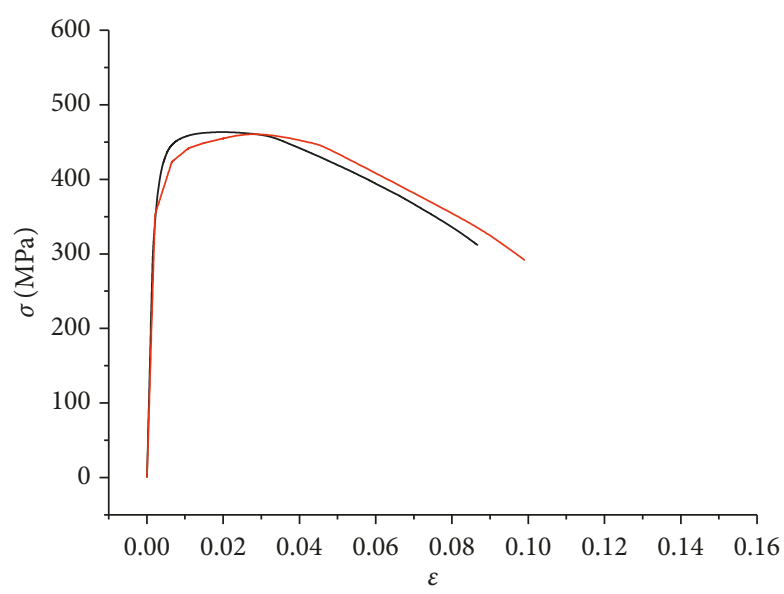

$$
\begin{aligned}
& \rho=7.25 \% \\
& -\quad \text { Experimental values } \\
& \text { Calculated values }
\end{aligned}
$$

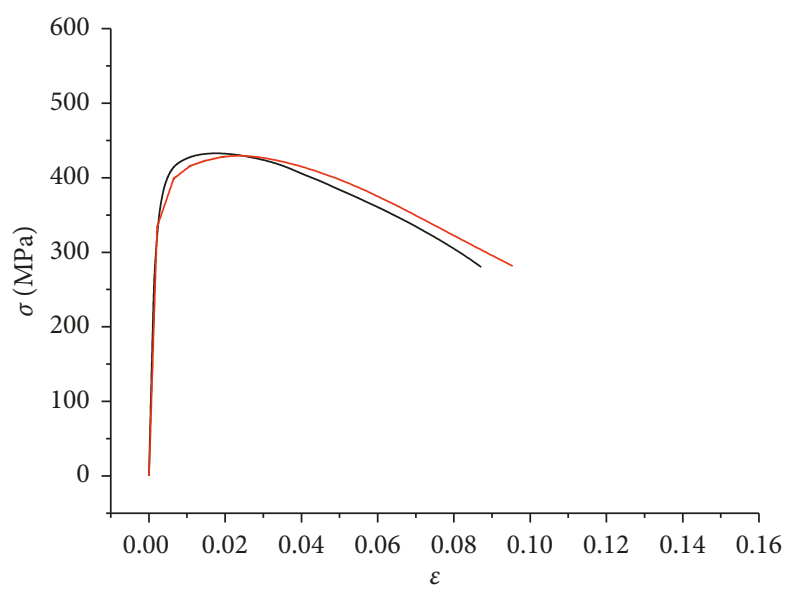

$$
\begin{aligned}
& \rho=9.36 \% \\
& -\quad \text { Experimental values } \\
& \text { Calculated values }
\end{aligned}
$$

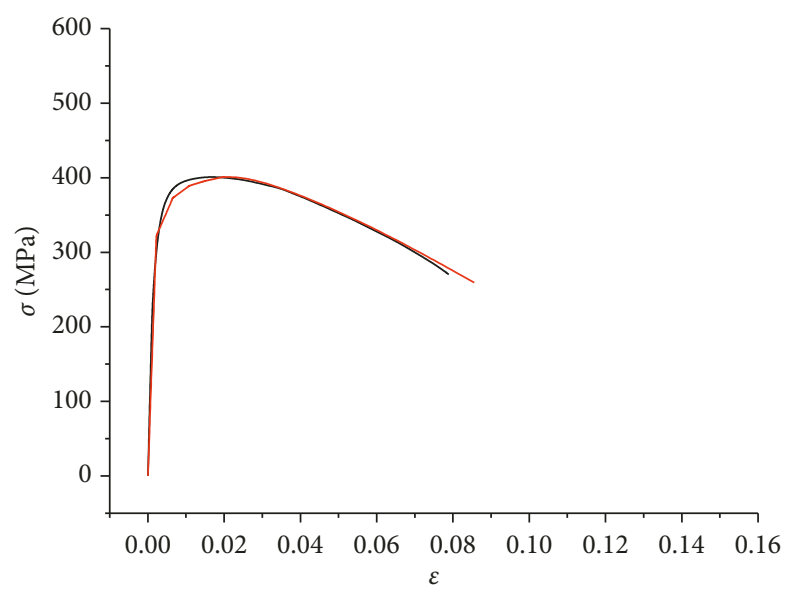

$\rho=14.21 \%$

$\rho=18.83 \%$

— Experimental values

_ Calculated values

FIGURE 12: Experimental versus calculated nominal stress-strain curves for studs corroded at different rates. 
agree well with the measured curves. The values of the constitutive parameters and material failure parameters which are applicable on the GTN model for the corroded studs are listed in Table 3.

The tensile processes of the corroded stud were numerically simulated in ABAQUS finite element software. Figure 10 shows the damage evolution processes of three series for different corrosion rates $(5.66 \%, 9.36 \%$, and $18.83 \%)$ where VVF represents the void volume fraction. In the initial stage, VVF was the stud corrosion rate. As the test progressed, VVF increased and the necking phenomenon gradually emerged in the local concentration. When the force approached its maximum value, VVF spiked and the stud fractured. The neck shrinkage phenomenon of the stud became less obvious and elongation decreased dramatically as corrosion rate increased. The failure mode of the model transferred from the typical plastic fracture to the brittle fracture mode at this point, which is consistent with the aforementioned results.

Figure 11 shows a comparison of the finite element simulation results with the actual test failure in terms of the failure modes. The failure modes are roughly consistent, but it is worth noting that the actual fracture location basically falls in the middle position. There are changes in the fracture position of the finite element simulation, however, which are mainly attributable to the selection of different GTN model parameters. This conclusion is also consistent with results previously published by $\mathrm{Xu}$ and Qian [16].

Figure 12 shows a comparison of the experimental and calculated nominal stress-strain curves for studs corroded at different rates. The results are in close agreement with maximum error less than $5 \%$. These results verify the feasibility of the GTN model for simulating the tensile properties of corroded studs, as well as the correctness of the parameters in Table 3.

\section{Conclusions}

(1) An equation for calculating the required time to achieve a predetermined corrosion rate was derived in this study based on Faraday's Law. Experimental results show that the theoretical corrosion rate predicted by this method is very close to the actual corrosion rate; this equation can feasibly be used to control stud corrosion rates. The theoretical prediction is slightly underestimated when the corrosion rate is less than or equal to $7 \%$ and slightly overestimated when the corrosion rate is greater than $7 \%$.

(2) The mechanical properties of the corroded studs were investigated via tensile tests. The results show that the yield strength, ultimate strength, and plastic properties of the corroded stud decrease as corrosion rate increases. However, the modulus of elasticity remains basically unchanged.

(3) The corrosion rate was characterized by the original void volume fraction and utilized to establish a relationship with material failure parameters. Simulation results indicate that the finite element calculations are in close agreement with test results. The GTN model can effectively simulate the uniaxial tensile behavior of corroded studs.

\section{Data Availability}

The data used to support the findings of this study are available from the corresponding author upon request.

\section{Conflicts of Interest}

The authors declare that there are no conflicts of interest regarding the publication of this paper.

\section{Acknowledgments}

This research was financially supported by the National Natural Science Foundation of China (no. 51808301) and the Zhejiang Natural Science Foundation (no. LQ19E080006). This work was also sponsored by K. C. Wong Magna Fund in Ningbo University.

\section{References}

[1] C. H. Chung, J. Lee, and J. S. Kim, "Shear strength of T-type perfobond rib shear connectors," KSCE Journal of Civil Engineering, vol. 20, no. 5, pp. 1824-1834, 2016.

[2] A. Song, S. Wan, Z. Jiang, and J. Xu, "Residual deflection analysis in negative moment regions of steel-concrete composite beams under fatigue loading," Construction and Building Materials, vol. 158, pp. 50-60, 2018.

[3] M. Zhou, Z. Liu, J. Zhang, L. An, and Z. He, "Equivalent computational models and deflection calculation methods of box girders with corrugated steel webs," Engineering Structures, vol. 127, pp. 615-634, 2016.

[4] J. Chen, Y.-x. Zhao, L. Wu, and W.-l. Jin, "Experimental investigation and design of corroded stud shear connectors," Advances in Structural Engineering, vol. 19, no. 2, pp. 218-226, 2016.

[5] T. Nakai, H. Matsushita, N. Yamamoto, and H. Arai, "Effect of pitting corrosion on local strength of hold frames of bulk carriers (1st report)," Marine Structures, vol. 17, no. 5, pp. 403-432, 2004.

[6] A. A. Almusallam, "Effect of degree of corrosion on the properties of reinforcing steel bars," Construction and Building Materials, vol. 15, no. 8, pp. 361-368, 2001.

[7] Y. Garbatov, C. Guedes Soares, J. Parunov, and J. Kodvanj, "Tensile strength assessment of corroded small scale specimens," Corrosion Science, vol. 85, no. 1, pp. 296-303, 2014.

[8] X. Feng, X. Lu, Y. Zuo, N. Zhuang, and D. Chen, "Electrochemical study the corrosion behaviour of carbon steel in mortars under compressive and tensile stresses," Corrosion Science, vol. 103, pp. 66-74, 2016.

[9] G. Chen, M. N. S. Hadi, D. Gao, and L. Zhao, "Experimental study on the properties of corroded steel fibres," Construction and Building Materials, vol. 79, pp. 165-172, 2015.

[10] W. Zhang, X. Liu, and X. Gu, "Fatigue behavior of corroded prestressed concrete beams," Construction and Building Materials, vol. 106, pp. 198-208, 2016.

[11] T. Guo, Z. Chen, T. Liu, and D. Han, "Time-dependent reliability of strengthened PSC box-girder bridge using phased 
and incremental static analyses," Engineering Structures, vol. 117, pp. 358-371, 2016.

[12] Z. Liu, T. Guo, M. H. Hebdon, and Z. Zhang, "Corrosion fatigue analysis and reliability assessment of short suspenders in suspension and arch bridges," Journal of Performance of Constructed Facilities, vol. 32, no. 5, Article ID 04018060, 2018.

[13] M. R. Bayoumi, A. A. Ismail, and A. K. Abd El Latif, "Finite element analysis of stresses due to pitting of steel specimens under different cyclic bending stresses," Engineering Fracture Mechanics, vol. 53, no. 1, pp. 141-151, 1996.

[14] J. K. Paik, J. M. Lee, and M. J. Ko, "Ultimate shear strength of plate elements with pit corrosion wastage," Thin-Walled Structures, vol. 42, no. 8, pp. 1161-1176, 2004.

[15] A. Shterenlikht and N. A. Alexander, "Levenberg-Marquardt vs Powell's dogleg method for Gurson-Tvergaard-Needleman plasticity model," Computer Methods in Applied Mechanics and Engineering, vol. 237-240, pp. 1-9, 2012.

[16] Y. Xu and C. Qian, "Application of gurson-tvergaard-needleman constitutive model to the tensile behavior of reinforcing bars with corrosion pits," PLoS One, vol. 8, no. 1, Article ID e54368, 2013.

[17] A. L. Gurson, "Continuum theory of ductile rupture by void nucleation and growth: part 1-yield criteria and flow rules for porous ductilr media," Journal of Engineering Materials and Technology, vol. 99, no. 1, pp. 2-15, 1977.

[18] V. Tvergaard, "Influence of voids on shear band instabilities under plane strain conditions," International Journal of Fracture, vol. 17, no. 4, pp. 389-407, 1981.

[19] J. Chen, H. Zhang, and Q.-Q. Yu, "Static and fatigue behavior of steel-concrete composite beams with corroded studs," Journal of Constructional Steel Research, vol. 156, pp. 18-27, 2019.

[20] S. A. Alghamdi and S. Ahmad, "Service life prediction of RC structures based on correlation between electrochemical and gravimetric reinforcement corrosion rates," Cement and Concrete Composites, vol. 47, no. 47, pp. 64-68, 2014.

[21] H. T. Nguyen and S. E. Kim, "Finite element modeling of push-out tests for large stud shear connectors," Journal of Constructional Steel Research, vol. 65, no. 10-11, pp. 19091920, 2009.

[22] J. Sun, Q. Huang, and Y. Ren, "Performance deterioration of corroded RC beams and reinforcing bars under repeated loading," Construction and Building Materials, vol. 96, pp. 404-415, 2015.

[23] W. Zhang, X. Song, X. Gu, and S. Li, "Tensile and fatigue behavior of corroded rebars," Construction and Building Materials, vol. 34, no. 5, pp. 404-419, 2012.

[24] B. Younise, M. Rakin, B. Medjo, and A. Sedmak, "Numerical simulation for studying constraint effect on ductile fracture initiation using complete Gurson model," FME Transactions, vol. 38, pp. 197-202, 2010.

[25] V. Tvergaard and J. W. Hutchinson, "The relation between crack growth resistance and fracture process parameters in elastic-plastic solids," Journal of the Mechanics and Physics of Solids, vol. 40, no. 6, pp. 1377-1397, 1992.

[26] A. S. Genikomsou and M. A. Polak, "Finite element analysis of punching shear of concrete slabs using damaged plasticity model in ABAQUS," Engineering Structures, vol. 98, pp. 38$48,2015$.

[27] M. Springmann and M. Kuna, "Identification of material parameters of the Gurson-Tvergaard-Needleman model by combined experimental and numerical techniques," Computational Materials Science, vol. 33, no. 4, pp. 501-509, 2005.
[28] C. C. Chu and A. Needleman, "Void nucleation effects in biaxially stretched sheets," Journal of Engineering Materials and Technology, vol. 102, no. 3, pp. 249-256, 1980.

[29] N. Aravas, "On the numerical integration of a class of pressure-dependent plasticity models," International Journal for Numerical Methods in Engineering, vol. 24, no. 7, pp. 1395-1416, 2010.

[30] Z. L. Zhang, C. Thaulow, and J. Ødegård, "A complete Gurson model approach for ductile fracture," Engineering Fracture Mechanics, vol. 67, no. 2, pp. 155-168, 2000.

[31] O. West, J. Lian, S. Münstermann, and W. Bleck, "Numerical determination of the damage parameters of a dual-phase sheet steel," ISIJ International, vol. 52, no. 4, pp. 743-752, 2012. 


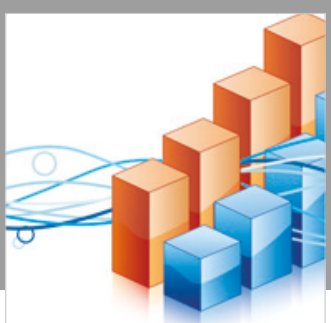

Advances in

Operations Research

\section{-n-m}
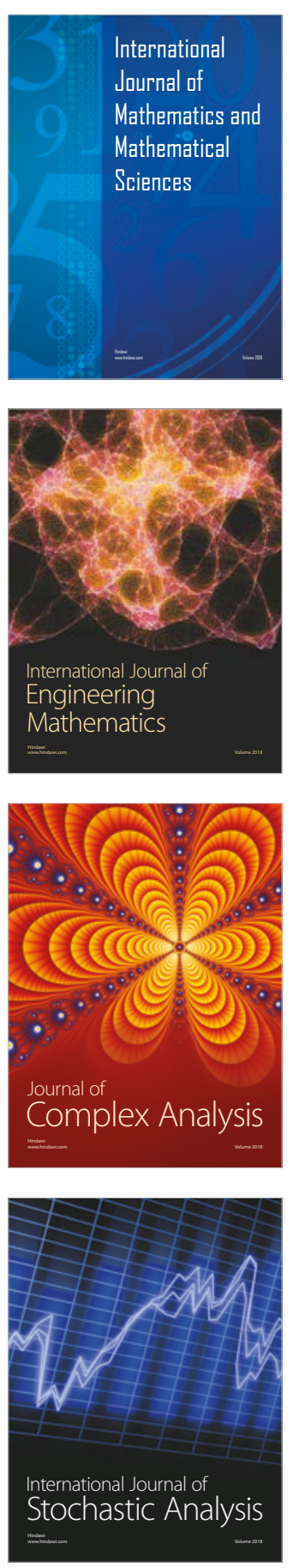
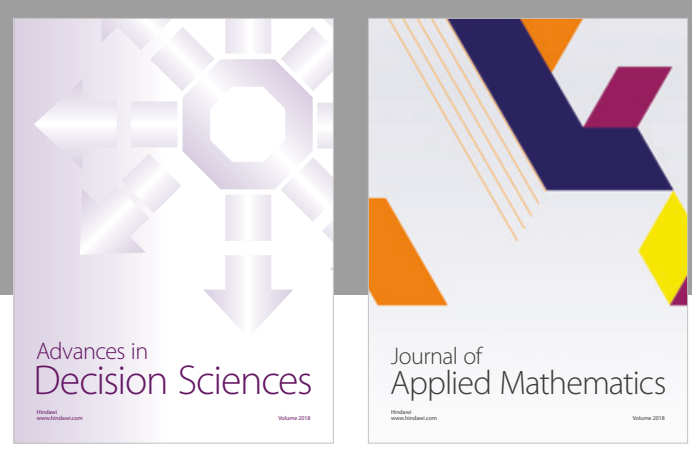

Journal of

Applied Mathematics
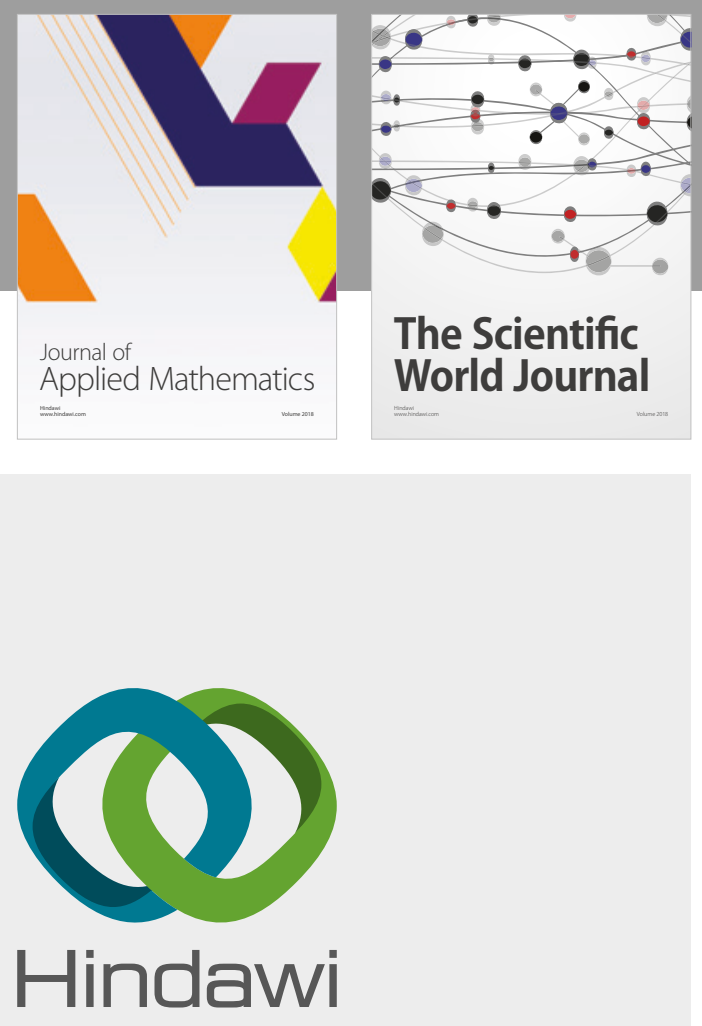

Submit your manuscripts at

www.hindawi.com

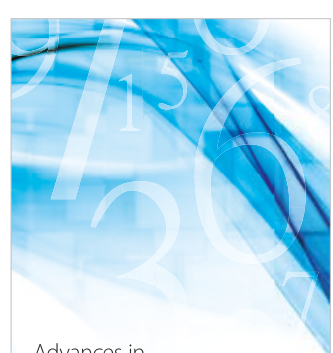

Advances in
Numerical Analysis
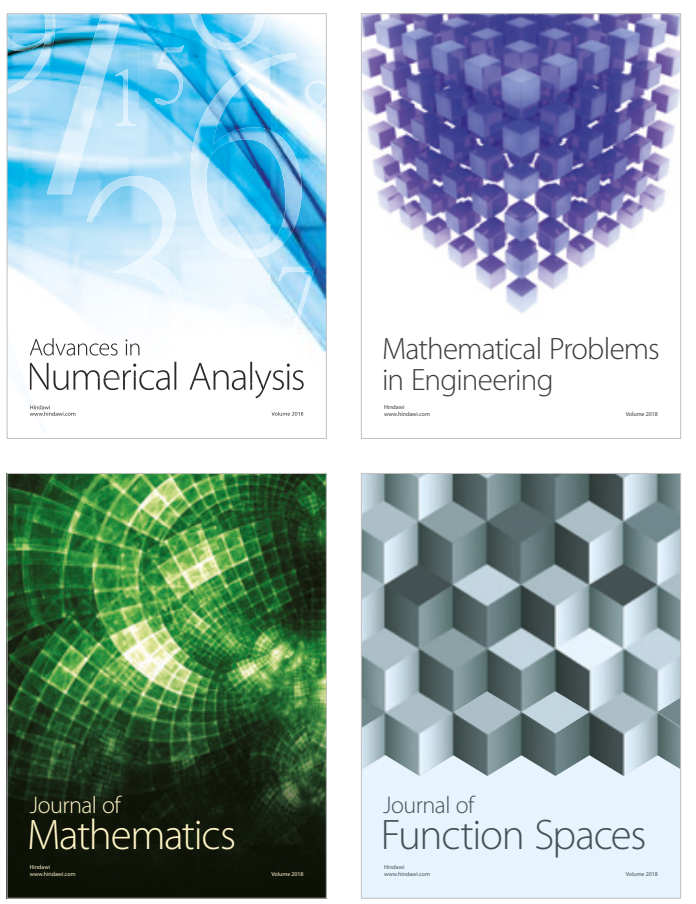

Mathematical Problems in Engineering

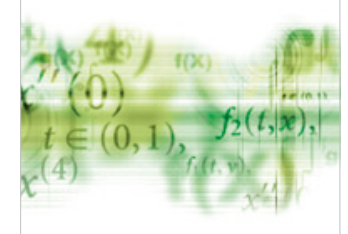

International Journal of

Differential Equations

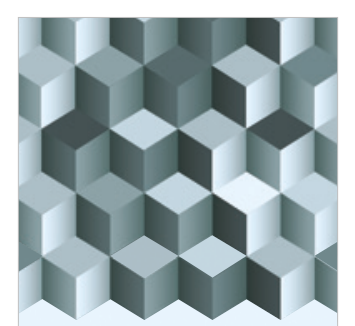

Journal of

Function Spaces
The Scientific

World Journal

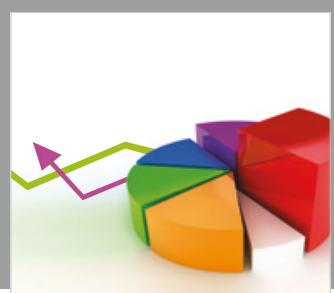

Journal of

Probability and Statistics
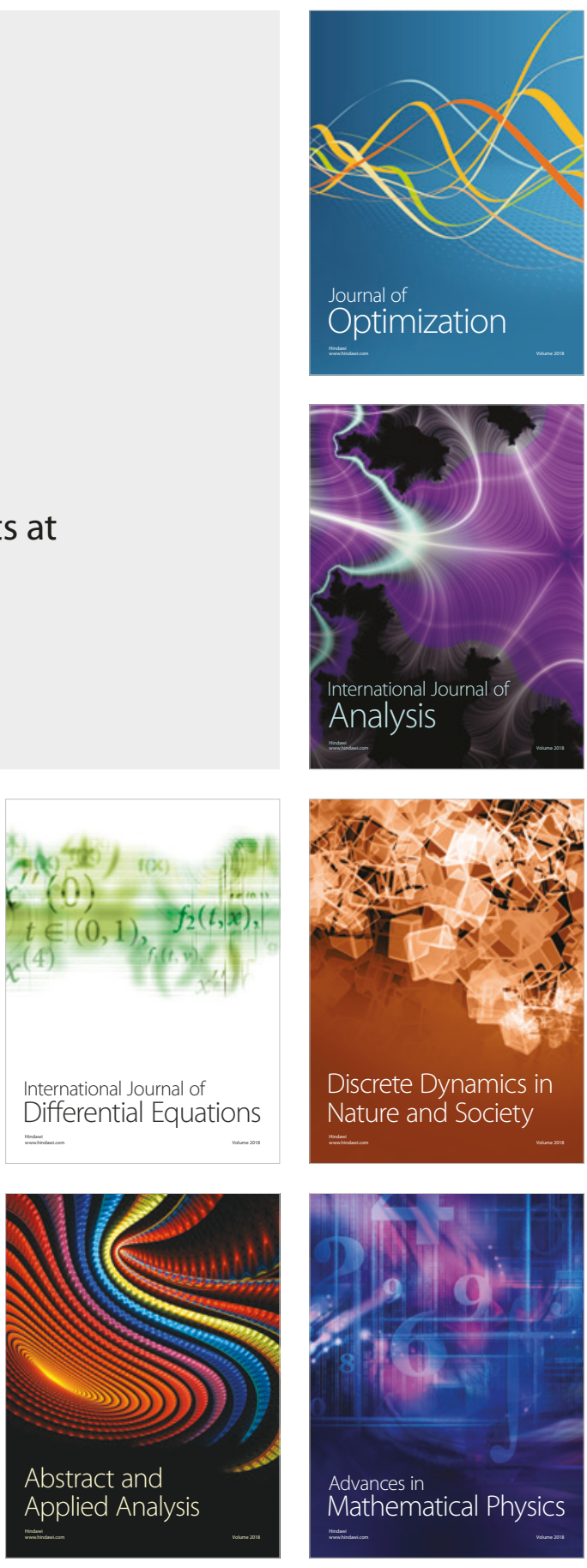